\title{
HIV-I CRF 02 AG polymerase genes in Southern Ghana are mosaics of different 02 AG strains and the protease gene cannot infer subtypes
}

\author{
Kwamena W Sagoe*1, Magda Dwidar², Theophilus K Adiku ${ }^{1}$ and \\ Max Q Arens ${ }^{2}$
}

Address: ${ }^{1}$ Clinical Virology Laboratory, Department of Microbiology, University of Ghana Medical School, PO Box 4236, Accra, Ghana and ${ }^{2}$ Retrovirus Laboratory, Department of Pediatrics, Washington University Medical School, St Louis, Missouri 63110, USA

Email: Kwamena W Sagoe* - kwcsagoe@chs.edu.gh; Magda Dwidar - Dwidar_M@kids.wustl.edu; Theophilus K Adiku - tekadiku@yahoo.com; Max Q Arens - Arens@kids.wustl.edu

* Corresponding author

Published: 26 February 2009

Virology Journal 2009, 6:27 doi:10.1186/1743-422X-6-27

This article is available from: http://www.virologyj.com/content/6/1/27

(C) 2009 Sagoe et al; licensee BioMed Central Ltd.

This is an Open Access article distributed under the terms of the Creative Commons Attribution License (http://creativecommons.org/licenses/by/2.0), which permits unrestricted use, distribution, and reproduction in any medium, provided the original work is properly cited.
Received: 23 December 2008

Accepted: 26 February 2009

\begin{abstract}
Background: Little is known about the detailed phylogeny relationships of CRF 02_AG HIV-I polymerase genes in Ghana. The use of the protease gene of HIV-I for subtyping has shown conflicting results.

Methods: The partial polymerase gene sequences of $25 \mathrm{HIV}-\mathrm{I}$ strains obtained with Viroseq reagents were aligned with reference subtypes and alignments trimmed to a 300 bp protease, $66 \mathrm{I}$ bp and 1005 reverse transcriptase sequence alignments. Phylogenetic relationships of these alignments were determined with the Neighbour-Joining method using 1000 replicates and recombination patterns determined for the sequences with RIP 3.0 in the HIV sequence database.

Results: Unlike the other alignments, the protease gene had nodes with bootstrap values $<100 \%$ for repeat control sequences. Majority of the CRF 02_AG sequences from Ghana were made up of fragments of several strains of CRF 02_AG/AG strains. The protease gene alone is not suitable for phylogenetic analysis.

Conclusion: The polymerase genes of HIV-I strains from Ghana are made up of recombinants of several CRF 02_AG strains from Ghana, Senegal and Cameroon, but the clinical implications are unknown. Using the HIV-I protease gene for subtyping will not infer subtypes correctly.
\end{abstract}

\section{Introduction}

HIV-1 strains can be divided into three genetic groups ( $M$, $\mathrm{N}$ and $\mathrm{O}$ ) with the group $\mathrm{M}$ further divided into 9 pure subtypes [1-3]. Recombination has however led to the circulation of mosaic HIV-1 strains, and these include the circulation of circulating recombinant forms (CRF) which play an important role in the epidemic [4-9].
Several studies have used the polymerase ( $p o l)$, protease (prot.), and reverse transcriptase (RT) genes for phylogeny [9-19]. Also, the pol gene has been shown to be useful for subtyping in areas with multiple subtypes [17]. In settings where the CRF 02_AG is found, fragments of the RT gene have been shown to provide a useful method for HIV-1 subtyping $[9,12,14,15,17,18]$. However, there are con- 
flicting reports on the usefulness of the prot. gene for subtype classification $[12,14,15,18]$.

In Ghana, the predominant subtype for the prot. gene is most likely to be CRF 02 AG [14]. Furthermore, it has recently been shown with HIV-1 envelope-glycoprotein gene (env-gp41) and pol sequences that most HIV-1 strains do not have strong phylogenetic relationships with each other $[20,21]$, suggesting an extremely variable relationship between strains. Since the role of subtypes and recombinants in primary resistance to antiretroviral drugs is still evolving and therefore unclear, subtyping of all HIV-1 strains will be needed with resistance testing for patients failing therapy in countries with non-subtype B strains. With the scale-up of antiretroviral therapy in Ghana, there is an increased need to perform resistance testing for patients adhering to treatment, but still have elevated viral loads despite prolonged therapy. Since commercial kits like the ABI/Celera ViroSeq reagents (Celera Diagnostics, Foster City, CA) are expensive for drug resistance testing [11], the likelihood is that in-house assays will be developed for the prot. and partial $R T$ regions and these fragments will also be used for subtype classification.

This study therefore determined the suitability of using the prot. and partial RT gene fragments of CRF 02_AG/AGlike sequences from Ghana which could be used for drug resistance testing, for subtype classification. The purity of the HIV-1 strains with respect to CRF 02_AG/AG-like strains involved in recombination were also looked at.

\section{Methods}

Sequencing of polymerase gene

Sequences from 25 patients infected with HIV-1 who attended the Fevers Unit at the Korle-Bu Teaching Hospital in Accra, Ghana, in 2003 were used for this study. The drug resistance mutations have been published recently [21]. Polymerase (pol) gene sequences were obtained using the ABI/Celera ViroSeq reagents (Celera Diagnostics, Foster City, CA) and this has been described elsewhere [11]. The nucleotide sequence data have been submitted to the NCBI database [GenBank: EF174555 to EF174569 and EF550529 to EF550538].

\section{Phylogenetic analysis}

Sequence homology of the 25 sequences (GHN sequences) was done with the HIV Blast Search in the HIV sequence database http://www.hiv.lanl.gov/content/hiv$\mathrm{db} /$ BASIC BLAST/basic blast.html with a pair wise comparison. The sequences with the highest homology $(\mathrm{n}=$ 13) to the GHN sequences were aligned with HIV-1 reference subtypes and the 25 sequences obtained from Ghana using the Clustal W software in BioEdit version 5.0.6 ftp:/ /iubio.bio.indiana.edu/molbio/seqpup/.
Two of the sequences obtained from the Blast Search CRF 02_AG from Cameroon (MP569 [GenBank: AM279387]) and a subtype G from Nigeria (NG083 [GenBank: U88826]) were confirmed as already in the reference subtypes by a conservation plot using BioEdit. They were however included as internal controls (repeat sequences) for phylogeny. From this original alignment which was 1305 bp long ( $p o l$.), three additional files were created by trimming sequences so as to obtain alignments with different base lengths: 300 bp prot., 661 bp $R T$ (RTs) and $1005 R T$. The four alignments were exported in the Raw Text format to the PHYLIP software v3.66 http://evolu tion.genetics.washington.edu/phylip.html and used for tree building. The RTs sequence includes amino acids 30 to 227 of the RT gene [22], and contains all the important drug resistance mutations for individual HIV-1 drugs currently being used in Ghana.

Distance estimations were done using Dnadist with the Kimura 2-parameter model [23], with the transition-totransversion (T/S) ratios that built the best possible phylogenetic tree. The Neighbor-joining analysis was then used to create phylogenetic trees with 1000 datasets and trees rooted with an HIV-1 group O strain (MVP5180 [GenBank: L20571]). In order to build robust trees, SeqBoot was used to build 1000 replicates before distances were estimated. The $\mathrm{T} / \mathrm{S}$ ratio was determined by using the Dnaml.exe file in the PHYLIP software to determine the maximum likelihood of obtaining the best tree. For each alignment (pol, prot., RTs, and RT), the likelihood of having the best tree was determined by running the Dnaml.exe with a T/S ratio from 1 to 4 with incremental differences of 0.05 . Since trees were going to be rooted with HIV-1 group O as an out-group, the MVP5180 strain was used as an out-group in Dnaml.exe for the T/S analysis. A consensus tree was built with Consense after Neighbor-joining and rooted with the MVP5180. Phylogenetic trees were displayed with the Molecular Evolutionary Genetics Analysis (MEGA) software version 4.0. Bootstrap values of $70 \%$ were considered as being phylogenetically significant.

\section{Recombination and CRF02_AG out-groups}

Recombination analysis was done with RIP 3 in the HIV sequence database http://www.hiv.lanl.gov/content/hiv$\mathrm{db} / \mathrm{RIP} 3 / \mathrm{RIP} . \mathrm{html}$ with the 13 sequences obtained from the Blast Search as a background sequence alignment. After input of query sequences, the RIP 3 output was rerun to identify fragments of the GHN sequences which had high homologies to the sequences in the background sequence alignment. The window size for the analysis was set at 500 nucleotides because subtype inference for CRF 02_AG strains from Ghana have been done with a similar length of nucleotides [6]. The significant threshold for the RIP program was set at $90 \%$. 
Of the 25 GHN sequences, 22 were CRF 02_AG and 2 were unclassified. These 24 sequences were also aligned in a separate file and the $\mathrm{T} / \mathrm{S}$ ratio for the best tree determined as described earlier. No out-group in Dnaml.exe was chosen for this T/S analysis and bootstrapping (1000 replicates) and Neighbor-Joining were used to infer phylogenetic relationships between the sequences. Trees were not rooted in Neigbor.exe (PHYLIP) and each sequence was subsequently used as an out-group and bootstrap values inferred in TreeView http://taxonomy.zool ogy.gla.ac.uk/rod/treeview.html after a consensus tree was built with Consense.

\section{Results}

\section{Phylogenetic relationships}

The T/S values for the likelihood of the best phylogenetic tree differed for each group of sequences analyzed. For the pol, prot, RT, and RTs, the values were 3.00, 1.85, 3.10 and 3.25 respectively. The file with the Ghana pol strains only had a $\mathrm{T} / \mathrm{S}$ of 3.05 .

For the pol. and RT, GHN CRF 02_AG sequences were inferred with sufficient confidence ( $\geq 70 \%)$, but the RTs and prot. had bootstrap values of $57 \%$ and $22 \%$ respectively. Sequences which were repeated had 100\% bootstrap values at their nodes for the pol., RT, and RTs, but not the prot. Although the CRF 02_AG from Cameroon [GenBank: AM279387] and one of the reference subtypes [GenBank: AJ286937] were shown to have the same nucleotide sequences, the node for the two sequences had bootstrap value of 59\% for the prot. alignment (Figure 1a). The subtype G from Nigeria [GenBank: $\underline{\text { U88826] }}$ ] that was repeated in the sequence alignment as U88826_R had bootstrap value of $67 \%$ for the prot. alignment (Figure 1a). The bootstrap values for the CRF 02_AG strains were 70\% for $R T$ and $57 \%$ for $R T$ s, but their tree topologies were similar.

\section{Recombination patterns/Out-groups}

Apart from GHN60, which was a subtype G, and GHN36 that was closely related to a CRF02_AG sequence from Ghana [GenBank: $\underline{A B 286862]}$, all the GHN sequences were recombinants of various CRF 02_AG/AG-like strains from Ghana, Cameroon and Senegal [see Additional file 1]. One of the two unclassified strains (GHN21) was a recombinant of an AG recombinant (AG_CM [AM279381] ) and a CRF 02_AG strain from Cameroon (02_AG CM [DQ166391]). The most frequent CRF02_AG fragments found were strains from Cameroon [GeneBank: AJ286952, $\underline{A}$ 286956] and Senegal [GeneBank: AJ286994] [see Additional file 1]. Minor drug resistance mutations have recently being shown in the GHN sequences used in this study [21], but there was no obvious relationship between the nature of recombination and the mutations seen. Details of CRF02_AG/AG recom- binant patterns for all sequences have been shown [see Additional file 1].

Even when considering a 90\% homology of GHN sequences to those used as background in the RIP program, some level of recombination between CRF 02_AG and AG strains do occur. GHN36 and GHN60 were the only pure strains [see Additional file 1]. The phylogenetic relationships between the Ghana sequences alone showed that GHN90 and GHN21 (together with GHN117) were significantly presented as out-groups with very high bootstrap values ( $>96 \%$ ). None of the other sequences had significant bootstrap values as out-groups.

\section{Discussion}

In this study, we trimmed sequences from a partial pol gene which included the prot. gene of HIV-1 sequences from Ghana. The results of this study unlike others presented the opportunity to determine phylogenetic relationships as the sequences were shortened from longer fragments and not by sequencing partial pol genes of the HIV-1 strains $[15,17,18]$. Our results indicate that the T/S values are different for different lengths of sequences and should be considered when building trees with fragments of the pol gene. The similarity in topology between RTs and $R T$ shows that the 661 bp can be confidently used for subtyping of HIV-1 strains from Ghana.

Similar length of sequences in the env as compared to the prot. have been used to establish phylogenetic relationship in HIV-1 strains from Ghana [6]. This may mean that the variability in the prot gene, especially for CRFs, may not be sufficient to establish strain relationships. Our results for the prot. phylogeny are in contrast to that of others $[12,14,15]$, but confirm the study by Pasquier et al [18]. The differences obtained from these studies are likely to be mainly due to the number of reference subtypes included. It is therefore important that in determining the true relationships of sequences, at least the nine pure subtypes and circulating recombinants commonly found within the region under study, are used for tree building. The subtyping done by Kinomoto et al. using only the prot. gene may therefore not be reliable [14].

The repeat sequences introduced had bootstrap values of $100 \%$ for the pol, RT and RTs phylogenetic trees but not prot. It can therefore be inferred that using a bootstrap value of $70 \%$ for the $R T$ and $57 \%$ for the RTs which accounted for the CRF 02_AG cluster will be sufficient to determine subtypes. Although other studies have used higher values, our results indicate that it may be necessary to include repeat reference sequences in order to ascertain the reliability of the length of sequences being used for bootstrapping analysis. Since the repeat sequences in the prot. gene had bootstrap values $<100 \%$, which did not 

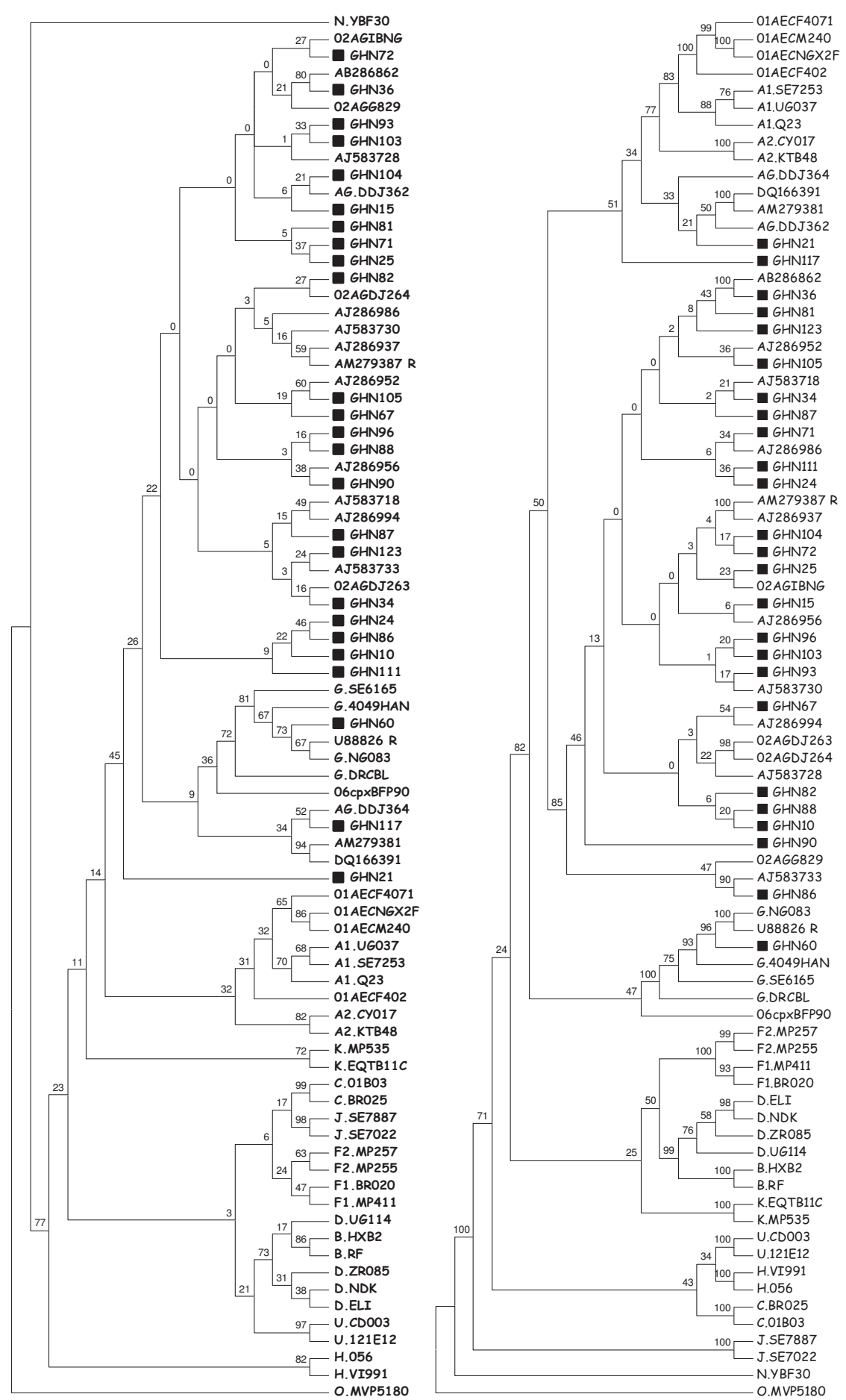

Figure I

Phylogenetic trees of sequences from 25 HIV-I infected patients from Ghana showing relationships of the (a) 300 bp protease (left) and (b) 1305 bp partial polymerase genes (right). Reference subtypes have been prefixed; sequences with accession numbers are sequences obtained by HIV Blast Search. CRF 02_AG sequence with accession number AM279387_R and subtype G with accession number U88826_R are repeat sequences used as internal controls for phylogeny. The CRFs begin with 02 (CRF 02_AG), 0 I (CRF 0I_AE) and 06 (CRF 06_CPX). The sequences used in this study have been indicated by a filled square. 
reflect in the others, this test can be used as a standard to test for the reliability for HIV-1 phylogeny rather than arbitrarily fixing bootstrap values that support the confidence of relationships.

Our results confirm those of other studies that the pol and $R T$ genes are useful for subtyping $[17,18]$. The loosely arranged pol gene sequences in the phylogenetic trees also reflected in the recombination analysis done, and confirm loosely arranged HIV-1 strains in previous studies [20]. Fragments of a previously characterized Ghanaian 02-AG sequence [GeneBank: $\underline{\mathrm{AB} 286862}$ (4 in Additional file 1)] were found in only two sequences, GHN36 and GHN81 [see Additional file 1]. Since GHN36 was the only pure 02_AG strain found, this may suggest that the pol genes may have evolved away from this prototype into other sequences. The pol gene of 02_AG sequences may be undergoing complex recombination processes that may further complicate its use for subtyping. Furthermore, since GHN90 was clearly an out-group when the 24 Ghana sequences were analyzed alone, it is likely that the evolution is towards that strain. This may explain why fragments of CRF 02_AG strains [GeneBank: AJ286956 (5 in Additional file 1)] and [GeneBank: AJ583728 (7 in Additional file 1)] which were common in GHN90 were frequently seen in other GHN sequences [see Additional file 1].

Although GHN21 and GHN117 did not cluster with significant reliability with the AG recombinant reference sequences DDJ362 [GeneBank: AY521632] and DDJ364 [GeneBank: AY521633] even in the pol gene (Figure 1b), this can be explained with the recombination analysis done [see Additional file 1]. GHN21 and GHN117 both had fragments of CRF 02_AG strains in their sequences, with GHN117 having 5 as compared to one in GHN21 [see Additional file 1]. It will be impossible to make these inferences about the purity of GHN21 and GHN117, and the other GHN strains [see Additional file 1], without the RIP analysis.

Thus, the polymerase genes of HIV-1 strains from Ghana are made up of recombinants of several CRF 02_AG strains from Ghana, Senegal and Cameroon, but the clinical implications are unknown. A continuous surveillance of pol gene sequences from Ghana is needed to understand this evolutionary pattern.

\section{Competing interests}

The authors declare that they have no competing interests.

\section{Authors' contributions}

KWS, MD, TKA and MQA designed the study, acquired the data and analyzed the results. The authors were also responsible for writing the manuscript.

\section{Additional material}

\section{Additional file 1}

Intra CRF 02_AG recombination patterns in the polymerase gene of HIV-1 strains from Southern Ghana. $I D_{G H N}$ are the sequence numbers (Ghana sequences) which have GenBank accession numbers EF174555 to EF174569 and EF550529 to EF550538; X represents the presence of sequences 1 to 13 in a particular $I D_{G H N}$ strain; the strains and assertion numbers of sequences 1 to 13 are: 1 (CRF 02_AG or 02_AG CM [미286952]), 2 (02_AG SN [ㅍ2286986]), 3 (02_AG CM,

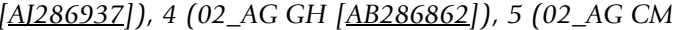
[AJ286956]), 6 (02_AG SN [시583718]), 7 (02_AG SN

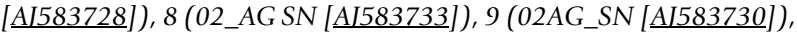
10 (recombinant AG_CM [AM279381]), 11 (02_AG CM [DQ166391]), 12 (subtype G NG [U188826]) and 13 (02_AG SN [A]286994]); reference sequences 1 to 13 were obtained by using the Blast Search in the HIV database to identify the closest sequences to the 25 sequences from Ghana; $\mathbf{T}_{\mathrm{CUM}}$ is the cumulative occurrence of reference sequences 1 to 13 in all the $25 I_{G H N}$ sequences; $\mathbf{T}$ represents the number of times strains 1 to 13 are seen in recombinants; $\boldsymbol{R}_{\text {СОмB }}$ are recombination patterns in $I D_{G H N}$ using sequences 1 to 13 as background sequences in the HIV RIP 3.0 program in the HIV Sequence Database; $S_{90 \%}$ represents stretches of nucleotides that had a homology of $\geq 90 \%$ in RIP anal$y$ sis (stretches a large window sizes and may not necessarily be continuous); nil, no recombination.

Click here for file

[http://www.biomedcentral.com/content/supplementary/1743422X-6-27-S1.doc]

\section{Acknowledgements}

The authors are grateful to Dr. Charles Brown of the School of Allied Health Sciences, College of Health Sciences, University of Ghana, for his useful comments.

\section{References}

I. Robertson DL, Anderson JP, Bradac JA, Carr JK, Foley B, Funkhouser RK, Gao F, Hahn BH, Kalish ML, Kuiken C, Learn GH, Leitner T, McCutchan F, Osmanov S, Peeters M, Pieniazek D, Salminen M, Sharp PM, Wolinsky S, Korber B: HIV-I nomenclature proposal. Science 2000, 288:55-56.

2. Simon F, Mauclere P, Roques P, Loussert-Ajaka I, Muller-Trutwin MC Saragosti S, Georges-Courbot MC, Barre-Sinoussi F, Brun-Vezinet F: Identification of a new human immunodeficiency virus type I distinct from group $\mathbf{M}$ and group $\boldsymbol{O}$. Nat Med 1998, 4:1032-1037.

3. Triques K, Bourgeois A, Vidal N, Mpoudi-Ngole E, Mulanga-Kabeya C, Nzilambi N, Torimiro N, Saman E, Delaporte E, Peeters M: Nearfull-length genome sequencing of divergent African HIV type I subtype $F$ viruses leads to the identification of a new HIV type I subtype designated K. AIDS Res Hum Retroviruses 2000, 16:139-15|

4. Carr JK, Salminen MO, Albert J, Sanders-Buell E, Gotte D, Birx DL, McCutchan FE: Full genome sequences of human immunodeficiency virus type I subtypes $\mathbf{G}$ and $\mathbf{A} / \mathbf{G}$ intersubtype recombinants. Virology 1998, 247:22-31.

5. Casado G, Thomson MM, Sierra M, Najera R: Identification of a novel HIV-I circulating ADG intersubtype recombinant form (CRFI9_cpx) in Cuba. J Acquir Immune Defic Syndr 2005, 40:532-537.

6. Fischetti L, Opare-Sem O, Candotti D, Sarkodie F, Lee H, Allain JP: Molecular epidemiology of HIV in Ghana: dominance of CRF02_AG. J Med Virol 2004, 73: I58-166.

7. Gao F, Robertson DL, Morrison SG, Hui H, Craig S, Decker J, Fultz PN, Girard M, Shaw GM, Hahn BH, Sharp PM: The heterosexual human immunodeficiency virus type I epidemic in Thailand 
is caused by an intersubtype (A/E) recombinant of African origin. J Virol 1996, 70:7013-7029.

8. Montavon C, Toure-Kane C, Liegeois F, Mpoudi E, Bourgeois A, Vergne L, Perret JL, Boumah A, Saman E, Mboup S, Delaporte E, Peeters M: Most env and gag subtype A HIV-I viruses circulating in West and West Central Africa are similar to the prototype AG recombinant virus IBNG. J Acquir Immune Defic Syndr 2000, 23:363-374

9. Tebit DM, Ganame J, Sathiandee K, Nagabila Y, Coulibaly B, Krausslich HG: Diversity of HIV in rural Burkina Faso. J Acquir Immune Defic Syndr 2006, 43: I44-152.

10. Agwale SM, Zeh C, Paxinos E, Odama L, Pienazek D, Wambebe C, Kalish ML, Ziermann R: Genotypic and phenotypic analyses of human immunodeficiency virus type $I$ in antiretroviral drugnaive Nigerian patients. AIDS Res Hum Retroviruses 2006, 22:22-26.

II. Eshleman SH, Hackett J Jr, Swanson P, Cunningham SP, Drews B, Brennan C, Devare SG, Zekeng L, Kaptue L, Marlowe N: Performance of the Celera Diagnostics ViroSeq HIV-I Genotyping System for sequence-based analysis of diverse human immunodeficiency virus type I strains. J Clin Microbiol 2004, 42:27II-27I7.

12. Fonjungo PN, Mpoudi EN, Torimiro IN, Alemnji GA, Eno LT, Lyonga EJ, Nkengasong JN, Lal RB, Rayfield M, Kalish ML, Folks TM, Pieniazek $D$ : Human immunodeficiency virus type I group $m$ protease in cameroon: genetic diversity and protease inhibitor mutational features. J Clin Microbiol 2002, 40:837-845.

13. Hue S, Clewley JP, Cane PA, Pillay D: HIV-I pol gene variation is sufficient for reconstruction of transmissions in the era of antiretroviral therapy. Aids 2004, 18:719-728.

14. Kinomoto M, Appiah-Opong R, Brandful JA, Yokoyama M, Nii-Trebi $\mathrm{N}$, Ugly-Kwame E, Sato H, Ofori-Adjei D, Kurata T, Barre-Sinoussi F, Sata T, Tokunaga K: HIV-I proteases from drug-naive West African patients are differentially less susceptible to protease inhibitors. Clin Infect Dis 2005, 4I:243-25I.

15. Lawrence P, Lutz MF, Saoudin H, Fresard A, Cazorla C, Fascia P, Pillet $S$, Pozzetto $B$, Lucht $F$, Bourlet $T$ : Analysis of polymorphism in the protease and reverse transcriptase genes of HIV type I CRF02-AG subtypes from drug-naive patients from SaintEtienne, France. J Acquir Immune Defic Syndr 2006, 42:396-404.

16. Nadembega WM, Giannella S, Simpore J, Ceccherini-Silberstein F, Pietra V, Bertoli A, Pignatelli S, Bellocchi MC, Nikiema JB, Cappelli G, Bere A, Colizzi V, Perno CP, Musumeci S: Characterization of drug-resistance mutations in HIV-I isolates from nonHAART and HAART treated patients in Burkina Faso. J Med Virol 2006, 78: I385-I39|.

17. Njouom R, Pasquier C, Sandres-Saune K, Harter A, Souyris C, Izopet $\mathrm{J}$ : Assessment of HIV-I subtyping for Cameroon strains using phylogenetic analysis of pol gene sequences. J Virol Methods 2003, II 0: I-8.

18. Pasquier C, Millot N, Njouom R, Sandres K, Cazabat M, Puel J, Izopet J: HIV-I subtyping using phylogenetic analysis of pol gene sequences. J Virol Methods 200I, 94:45-54.

19. Vicente AC, Agwale SM, Otsuki K, Njouku OM, Jelpe D, Idoko JA, Caride E, Brindeiro RM, Tanuri A: Genetic variability of HIV-I protease from Nigeria and correlation with protease inhibitors drug resistance. Virus Genes 200I, 22:18I-186.

20. Brandful JA, Coetzer ME, Cilliers T, Phoswa M, Papathanasopoulos MA, Morris L, Moore PL: Phenotypic characterization of HIV type I isolates from Ghana. AlDS Res Hum Retroviruses 2007, 23:144-152.

21. Sagoe KW, Dwidar M, Lartey M, Boamah I, Agyei AA, Hayford AA, Mingle JA, Arens MQ: Variability of the human immunodeficiency virus type I polymerase gene from treatment naive patients in Accra, Ghana. J Clin Virol 2007, 40:163-167.

22. Steegen K, Demecheleer E, De Cabooter N, Nges D, Temmerman M, Ndumbe $P$, Mandaliya $K$, Plum J, Verhofstede $C$ : A sensitive inhouse RT-PCR genotyping system for combined detection of plasma HIV-I and assessment of drug resistance. J Virol Methods 2006, 133:137-145.

23. Kimura $\mathrm{M}$ : A simple method for estimating evolutionary rates of base substitutions through comparative studies of nucleotide sequences. J Mol Evol 1980, 16: I II-I20.
Publish with Bio Med Central and every scientist can read your work free of charge

"BioMed Central will be the most significant development for disseminating the results of biomedical research in our lifetime. "

Sir Paul Nurse, Cancer Research UK

Your research papers will be:

- available free of charge to the entire biomedical community

- peer reviewed and published immediately upon acceptance

- cited in PubMed and archived on PubMed Central

- yours - you keep the copyright
BioMedcentral 